\title{
Material and Electrochemical Characterization of Tetrapropylammonium Manganese Oxide Thin Films as Novel Electrode Materials for Electrochemical Capacitors
}

\author{
Suk-Fun Chin, ${ }^{\text {a,* }}$ Suh-Cem Pang, ${ }^{\mathrm{b}, *}$ and Marc A. Anderson ${ }^{\mathrm{a}, * *, \mathrm{z}}$ \\ ${ }^{a}$ Environmental Chemistry and Technology Program, University of Wisconsin-Madison, \\ Madison, Wisconsin 53706, USA \\ ${ }^{b}$ Faculty of Resource Sciences and Technology, Universiti Malaysia Sarawak, Sarawak, Malaysia
}

\begin{abstract}
Stable colloidal tetrapropylammonium manganese oxide (TPA-MO) was formed by the reduction of tetrapropylammonium permanganate with 2-butanol at room temperature. Thin films of TPA-MO were prepared using the sol-gel process by dip-coating directly onto clean nickel foils followed by heat-treatment under controlled conditions. The microstructure evolution of TPA-MO films at various calcination temperatures was characterized using Brunauer-Emmett-Teller method, X-ray diffraction, and scanning electron microscopy. The performance of these films as supercapacitors was evaluated using cyclic voltammetry in various aqueous electrolytes. These thin films exhibited excellent capacitive behavior with a specific capacitance of $720 \mathrm{~F} / \mathrm{g}$. These films also showed good reversibility and cycling stability, losing little more than $20 \%$ of their charge capacity after 1500 cycles. (C) 2002 The Electrochemical Society. [DOI: 10.1149/1.1453406] All rights reserved.
\end{abstract}

Manuscript submitted May 15, 2001; revised manuscript received October 30, 2001. Available electronically February 19 , 2002.

Manganese oxides in their various forms have been widely studied and developed for applications in electrochemical energy conversion and storage systems. ${ }^{1-5}$ The superior electrochemical performance of these materials have made them attractive candidates for cathode materials in $\mathrm{MnO}_{2} / \mathrm{Zn}$ alkaline cells, ${ }^{1}$ as an intercalation host for lithium batteries, 2,3 and more recently as electrodes in ultracapacitors. ${ }^{4,5}$ As compared to other transition metal oxides such as $\mathrm{NiO}_{2}, \mathrm{CoO}, \mathrm{RuO}_{2}$, and $\mathrm{V}_{2} \mathrm{O}_{5}$, these materials have received much attention and interest due to the low cost of raw materials, low toxicity, and environmentally friendly character.

Studies of Pang et al. ${ }^{4,5}$ have shown that sol-gel-derived $\mathrm{MnO}_{2}$ thin films are a promising electrode material for supercapacitors due to their high reversibility, good cycling stability, and their high specific capacitance of $700 \mathrm{~F} / \mathrm{g}$. However, in spite of their favorable characteristics, the potential use of such sol-gel-derived $\mathrm{MnO}_{2}$ films for fabricating practical devices is limited by the very dilute concentration $\left(10^{-3} \mathrm{M}\right)$ of the $\mathrm{MnO}_{2}$ colloidal suspension employed in coatings. Stable nanoparticles of manganese oxides having higher concentrations are difficult to prepare because of the strong tendency of manganese oxides to precipitate or coagulate during synthesis. Any increase in the $\mathrm{MnO}_{2}$ concentration invariably leads to the destabilization of the colloidal suspension. Considerable efforts have therefore been directed toward exploring alternative precursors and approaches in order to prepare stable colloidal suspensions with higher concentrations of manganese dioxide particles.

Recently, stable colloidal manganese oxides with concentrations as high as $0.57 \mathrm{M}$ have been successfully prepared by incorporating tetralkylammonium cations (alkyl = ethyl, propyl, and butyl) to prevent agglomerization of the negatively charged manganese oxide particles. ${ }^{6}$ Materials derived from such colloidal manganese oxides are reported to have lamellar structure with tetraalkylammonium cations intercalated between the manganese oxide layers. The manganese oxides have an average oxidation state of 3.70-3.79. ${ }^{6}$ The pore size distribution of materials derived from such organic cation template-based manganese oxides can be well controlled by the size of the particles that constitute the templates, which can be subsequently removed by heat-treatment.

In this paper, we report on the microstructural characterization of sol-gel-derived tetraproplyammonium manganese oxide (TPA-MO) thin films on nickel substrates and the electrochemical characterization of these films when employed as electrochemical capacitors.

\footnotetext{
* Electrochemical Society Student Member.

** Electrochemical Society Active Member.

z E-mail: nanopor@facstaff.wisc.edu
}

\section{Experimental}

Stable colloidal suspension of tetrapropylammonium manganese oxide (TPA-MO) was prepared by the reduction of tetrapropylammonium permanganate with 2-butanol in aqueous solution at room temperature following the method reported by Brock et al. ${ }^{6}$ with some modifications in the synthesis procedure. TPA- $\mathrm{MnO}_{4}$ salt is added to a mixture of ultrapure (Milli-Q) water and 2-butanol in a volume ratio of $1: 1$ and stirred continuously for $2 \mathrm{~h}$. The 2-butanol layer was then removed using a separation funnel. The manganese concentration in the resulting TPA-MO suspension was measured by ICP/AES (inductively coupled plasma with atomic emission spectrometry). The size of the TPA-MO particle was determined by laser light-scattering technique using a Zetasizer $3000 \mathrm{HS}$ advanced mobility analyzer (Malvern Instruments, Inc). Mobility measurements were performed using the same instrument. The $\mathrm{pH}$ value was adjusted by adding nitric acid, $\mathrm{HNO}_{3}$.

Xerogels were prepared by evaporating a suspension of TPA-MO at ambient temperature. The Brunauer-Emmett-Teller (BET) surface area and pore volume were determined by the nitrogen gas adsorption-desorption method at $77 \mathrm{~K}$ using Micrometrics ASAP 2010. The pore size distribution was calculated by the BarrettJoyner-Halenda (BJH) method using the desorption branch of the isotherm. A Netszch STA 409 analyzer was used to perform the simultaneous thermogravimetric and differential thermal analyses (TG/DTA). Samples were heated from 25 to $800^{\circ} \mathrm{C}$ at a heating rate of $2^{\circ} \mathrm{C} / \mathrm{min}$ under a flowing air atmosphere. The flow rate was 20 $\mathrm{mL} / \mathrm{min}$ and $\alpha-\mathrm{Al}_{2} \mathrm{O}_{3}$ was used as the reference material. A Scintag diffractometer using $\mathrm{Cu} \mathrm{K} \alpha$ radiation was used to obtain the diffraction patterns of the sample calcined at various temperatures. A LEO scanning electron microscope (SEM) was used to characterize the microstructure of the TPA-MO thin films.

Thin films of TPA-MO were formed directly on clean nickel foils (0.125 $\mathrm{mm}$ in thickness) by dip-coating under a controlled withdrawal velocity. All nickel foils were thoroughly cleaned prior to deposition according to the method reported by Pang et al. ${ }^{4} \mathrm{~A}$ measured amount of sol was mixed with $0.8 \%(\mathrm{v} / \mathrm{v})$ of surfactant $(0.05 \%$ sodium dodecyl sulfate) in order to improve the adherence of sol unto the nickel substrate. The electrochemical properties of these thin films were studied with an EG\&G model 6310 potentiostat using a standard three-electrode cell configuration. Cyclic voltammetry was scanned over the potential range of 0.0-0.9 V, with a scan rate of $50 \mathrm{mV} / \mathrm{s}$ in various mild aqueous electrolytes. The reference electrode was a saturated calomel electrode (SCE) fitted with a bridge of Vycor frit, and the counter electrode was a platinum foil $\left(\sim 1.5 \mathrm{~cm}^{2}\right)$. The TPA-MO thin films were heat-treated at 100, 200, 300,400 , and $500^{\circ} \mathrm{C}$ in air for $1 \mathrm{~h}$. The charge capacity, which is 